\title{
Subacute Pulmonary Toxicity of Copper Indium Gallium Diselenide Following Intratracheal Instillations into the Lungs of Rats
}

\author{
Akiyo TAnAKA ${ }^{1}$, Miyuki HiratA ${ }^{1}$, Masaharu ShIRATANI ${ }^{2}$, \\ Kazunori KogA ${ }^{2}$ and Yutaka KIYOHARA ${ }^{1}$ \\ ${ }^{1}$ Department of Environmental Medicine, Graduate School of Medical Sciences, Kyushu University, Japan and \\ ${ }^{2}$ Department of Electronics, Graduate School of Information Science and Electrical Engineering, Kyushu University, \\ Japan
}

\begin{abstract}
Subacute Pulmonary Toxicity of Copper Indium Gallium Diselenide Following Intratracheal Instillations into the Lungs of Rats: Akiyo TANAKA, et al. Department of Environmental Medicine, Graduate School of Medical Sciences, Kyushu UniversityObjectives: The aim of this study was to clarify the pulmonary toxicity of copper indium gallium diselenide (CIGS) solar cells on 62 8-wk-old rats. Methods: Male Wistar rats were given $0.5,5$ or $50 \mathrm{mg} / \mathrm{kg}$ of CIGS particles, intratracheally, 3 times for a week. Control rats were given vehicle, distilled water, only. These rats were euthanized 0,1 or 3 wk after the final instillation serially, and toxicological effects were determined. Results: None of the CIGS-treated groups exhibited suppression of body weight gain compared with the control group. The relative lung weight in the CIGS $5 \mathrm{mg} / \mathrm{kg}$-treated and $50 \mathrm{mg} / \mathrm{kg}$-treated groups were significantly increased compared with that in the control group throughout the observation period. Although serum copper $(\mathrm{Cu})$ and selenium $(\mathrm{Se})$ concentrations were not affected by instillations of CIGS particles, the indium (In) levels increased with the passage of time in the CIGS $5 \mathrm{mg} / \mathrm{kg}$-treated and $50 \mathrm{mg} / \mathrm{kg}$-treated groups. However, the serum gallium ( $\mathrm{Ga}$ ) levels decreased in the CIGS $50 \mathrm{mg} / \mathrm{kg}$-treated group from 0 to $3 \mathrm{wk}$. The content of each metal in the lung increased depending on the dose instilled and was constant during observation periods. Histopathologically, foci of slight to severe pulmonary inflammatory response and exudation were present among all the CIGS-treated groups, and the severity of these lesions worsened with the passage of time. Conclusion: The present results clearly demon-
\end{abstract}

Received Aug 4, 2011; Accepted Jan 22, 2012

Published online in J-STAGE Mar 23, 2012

Correspondence to: A. Tanaka, Department of Environmental Medicine, Graduate School of Medical Sciences, Kyushu University, EC Bldg 2F, 6-10-1 Hakozaki, Higashi-ku, Fukuoka 812-8581, Japan (e-mail:atanaka@envmed.med.kyushu-u.ac.jp) strate that CIGS particles caused subacute pulmonary toxicity and that dissolution of CIGS particles in the lung was considerably slow when repeated intratracheal instillations were given to rats.

(J Occup Health 2012; 54: 187-195)

Key words: CIGS, Intratracheal instillation, Metal concentration, Pulmonary toxicity, Rats, Solar cells

Because interest in global environment problems has increased, the world volume of production of solar cells has increased rapidly in recent years. Copper indium gallium diselenide (CIGS), which is a new efficient thin film solar cell used in some types of solar cells, is used in roofing materials and various applications in aerospace and recreational industries ${ }^{1-3)}$. Since recent advancements in CIGS thin films have reduced production costs and improved performance, CIGS solar cell production continued to increase in 2010 in the global solar market, and it is estimated that the consumption of indium for solar cell manufacturing will become $30 \mathrm{t} / \mathrm{yr}$ in Japan within several years ${ }^{4}$. Although indium is a constitutive element of CIGS thin film solar cells, it was thought that indium compounds were not harmful until the beginning of the 1990s because there was little information regarding the adverse health effects on humans or animals arising from exposure to indium compounds. After the mid 1990s, data became available indicating that indium compounds can be toxic to animals ${ }^{5-20)}$. However, due to the increasingly frequent industrial use of indium, the potential occupational or environmental exposure to indium compounds has attracted much attention. Although there remained little information regarding the adverse health effects arising from exposure to indium compounds, the first case of 
interstitial pneumonia caused by occupational exposure to indium tin oxide (ITO) was reported in $2003^{21)}$. Following that first case report, interstitial pulmonary disorders in indium-processing workers have been reported by three epidemiological studies ${ }^{22-24)}$, as well as by several case reports ${ }^{25-29}$. A few toxicological studies of solar cell materials, such as copper gallium diselenide (CGS), copper indium diselenide (CIS) and cadmium telluride ( $\mathrm{CdTe})$, were carried out in the $1990 \mathrm{~s}^{30,31)}$, but there is no data available on the pulmonary toxicity of CIGS. On the other hand, the International Agency for Research on Cancer (IARC) evaluated gallium arsenide as carcinogenic to humans (Group 1) and indium phosphide (InP) as probably carcinogenic to humans (Group 2A) ${ }^{32,33}$ in 2006. Although arsenic and arsenic compounds have been evaluated as carcinogenic to humans (Group 1) by the IARC $^{34)}$, gallium (Ga) and indium (In) may be responsible for cancer manifestation. Since CIGS films are prepared by the method of multisource evaporation of $\mathrm{Cu}, \mathrm{In}, \mathrm{Ga}$ and $\mathrm{Se}$ in a growth chamber, a portion of CIGS may attach to the inner wall of the growth chamber ${ }^{35)}$. It is necessary to confirm whether or not exposure to CIGS is a potential health hazard for workers handling this material at the time of maintenance of growth chambers. There is a fair chance that the lung toxicity of CIGS will appear when exposure to CIGS is via the trachea.

In this study, therefore, we evaluated the subacute pulmonary toxic effects and each constitutive metal level in the lung or serum of CIGS particles when given to rats via intermittent intratracheal instillations. The dose instilled was set up 3 doses which was ratio of 10 times dose, maximum dose per one instillation was $50 \mathrm{mg} / \mathrm{kg}$, the double indium dose containing $6 \mathrm{mg} / \mathrm{kg}$ of ITO used in previous study ${ }^{17)}$.

\section{Materials and Methods}

\section{Test materials}

CIGS particles with a mean diameter of $1.6 \mu \mathrm{m}$ were obtained from the Research Center for Photovoltaics, Tsukuba, Ibaraki, Japan. The CIGS particles were comprised of $24 \mathrm{~mol} \%$ copper, $13 \mathrm{~mol} \%$ indium, $13 \mathrm{~mol} \%$ gallium and $50 \mathrm{~mol} \%$ selenium.

\section{Animal}

All sixty-two male Wistar rats were purchased at 7 wk of age from Kyudo Co., Ltd. (Tosu, Japan). The rats were kept in a conventional conditioned room until commencement of the experiment. The light cycle was 12 hours of light and 12 hours of dark; the temperature was $23-25^{\circ} \mathrm{C}$; and the air humidity was $50-60 \%$. Five or six rats were housed per stainless steel cage and fed a commercial diet (CE-2 pellets, Clea Japan, Inc., Tokyo, Japan), with drinking tap water available ad libitum. The intratracheal instillations were started in 8-wk-old rats after they had become acclimatized to the animal facility for $1 \mathrm{wk}$.

\section{Treatment}

Each instillation per animal comprised $0.5 \mathrm{mg} / \mathrm{kg}$ $(0.09 \mathrm{mg} / \mathrm{kg}$ of In), $5 \mathrm{mg} / \mathrm{kg}(0.9 \mathrm{mg} / \mathrm{kg}$ of In) or $50 \mathrm{mg} / \mathrm{kg}(9 \mathrm{mg} / \mathrm{kg}$ of In) of CIGS particles. The control rats received $1.0 \mathrm{~m} l / \mathrm{kg}$ of distilled water only. All the rats, which had a mean \pm SD weight of $294.8 \pm 10.4 \mathrm{~g}$, were randomized into 4 groups: the control group $(n=15)$, rats treated with a dose of $0.5 \mathrm{mg} / \mathrm{kg}$ of CIGS (CIGS $0.5 \mathrm{mg}$ group; $\mathrm{n}=15$ ), rats treated with a dose of $5 \mathrm{mg} / \mathrm{kg}$ of CIGS (CIGS $5 \mathrm{mg}$ group; $\mathrm{n}=15$ ) and rats treated with a dose of $50 \mathrm{mg} / \mathrm{kg}$ of CIGS (CIGS $50 \mathrm{mg}$ group; $\mathrm{n}=17$ ). There was no significant difference in body weight among the four groups at the start of the experiment. The average body weight at the beginning of the instillations was $290.2 \pm 9.6 \mathrm{~g}$ in the control group, $298.1 \pm 10.1 \mathrm{~g}$ in the CIGS $0.5 \mathrm{mg}$ group, $293.8 \pm 9.5 \mathrm{~g}$ in the CIGS $5 \mathrm{mg}$ group and $296.1 \pm 13.3 \mathrm{~g}$ in the CIGS $50 \mathrm{mg}$ group. These particles were suspended in sterile distilled water just prior to each instillation. Because the CIGS particles subsided in distilled water, suspensions of CIGS particles were prepared by stirring using a magnet-type stirrer. The concentration of the CIGS suspension was $0.5 \mathrm{mg} / \mathrm{ml}$ at the dosage of $0.5 \mathrm{mg} / \mathrm{kg}, 5 \mathrm{mg} / \mathrm{ml}$ at the dosage of $5 \mathrm{mg} / \mathrm{kg}$, $50 \mathrm{mg} / \mathrm{ml}$ at the dosage of $50 \mathrm{mg} / \mathrm{kg}$, respectively. Each dose in each group was given as an intratracheal instillation in a volume of $1.0 \mathrm{ml} / \mathrm{kg}$ suspension and was instilled into the trachea of the rats anesthetized with ether 3 times for a week. Body weight was measured at the time of each instillation. Rats were euthanized by carbon dioxide gas at $0 \mathrm{wk}$ (on the day after the final instillation), $1 \mathrm{wk}$ or $3 \mathrm{wk}$ following final instillation. Blood was collected from the posterior vena cava in all rats, and the serum was separated. Serum samples were then stored at $-80^{\circ} \mathrm{C}$ until analysis.

\section{Histopathological examination}

The lungs were removed and weighed. The lungs were prepared for histological examination. They were fixed in $10 \%$ neutral buffered formalin solution. Fixed tissues were embedded in paraffin, cut into $6-\mu \mathrm{m}$ sections, stained with hematoxylin-eosin or periodic acid Schiff reagent (PAS) and then examined by light microscopy. Histopathological findings in the lung were scored as present or absent; if they were absent, then the findings were expressed as negative. In the case of lung lesions, the severity of each lung lesion was graded on a scale ranging from slight to severe, indicating the approximate frac- 
tion of the lung or structure judged to be involved $($ slight $=1-10 \%$, mild $=11-24 \%$, moderate $=25-50 \%$ and severe $=51-100 \%$ ) .

Determination of the element concentration in the lung and serum

The apical lobe in the lung and serum samples from all the treated rats were analyzed for $\mathrm{Cu}$, In, $\mathrm{Ga}$ and Se concentrations. For pretreatment, an apical lobe was soaked in $10 \mathrm{ml}$ of $68 \%$ ultrapure nitric acid (TAMAPURE-AA-100, Tama Chemicals Co., Ltd., Kawasaki, Kanagawa, Japan) overnight. Both $0.1 \mathrm{~m} l$ of lung soak solution and $1 \mathrm{~m} l$ of serum were digested with $5 \mathrm{ml}$ of $68 \%$ ultrapure nitric acid (TAMAPURE-AA-100, Tama Chemicals Co., Ltd., Kawasaki, Kanagawa, Japan) and $0.5 \mathrm{ml}$ of $35 \%$ ultrapure hydrogen peroxide (TAMAPURE-AA-100, Tama Chemicals Co., Ltd., Kawasaki, Kanagawa, Japan) by a microwave digestion apparatus (Multiwave 3000, PerkinElmer, Japan). Digested samples were diluted to $20 \mathrm{~m} l$ with ultrapure water and introduced into an inductively coupled plasma mass spectrometer (ICP-MS, Agilent 7500ce, Agilent Technologies, Tokyo, Japan) at the Center of Advanced Instrumental Analysis, Kyushu University. Rhodium was used as an internal standard for metal measurement. The quantitative limit values for serum were $6 \mu \mathrm{g} / l$ for $\mathrm{Cu}, 0.1 \mu \mathrm{g} / l$ for In, $0.2 \mu \mathrm{g} / l$ for $\mathrm{Ga}$ and $30 \mu \mathrm{g} / l$ for Se. Those for the lung were $3 \mu \mathrm{g} / l$ for $\mathrm{Cu}, 0.03 \mu \mathrm{g} / l$ for $\mathrm{In}, 0.07 \mu \mathrm{g} / l$ for $\mathrm{Ga}$ and $2 \mu \mathrm{g} / l$ for Se. If the serum $\mathrm{Cu}, \mathrm{In}, \mathrm{Ga}$ or $\mathrm{Se}$ concentration was below the quantitative limit value, a half value of each concentration was given for the statistical analysis. The metal content in the whole lung was calculated for each metal from the concentration of each metal in lung tissue.

Data on body weight were analyzed by two-way repeated measure ANOVA. Fischer's least significant difference procedure was used in the case of organ weight after one-way analysis of variance. In all the statistical comparisons, a $p$ value of less than 0.05 was used to determine significant differences.

These experiments were conducted according to the Guidelines for Animal Experiments in the Graduate School of Medical Sciences, Kyushu University, and in compliance with Law No. 105 and Notification No. 6 of the Government of Japan.

\section{Results}

The mean total dosage of CIGS particles received per animal (mean $\pm \mathrm{SD}$ ) was $0.5 \pm 0.0 \mathrm{mg}$ in the CIGS $0.5 \mathrm{mg}$ group, $4.6 \pm 1.7 \mathrm{mg}$ in the CIGS $5 \mathrm{mg}$ group and $47.2 \pm 1.6 \mathrm{mg}$ in the CIGS $50 \mathrm{mg}$ group. No rats died during the instillation period or the observation period.

Intratracheal instillations of CIGS particles did

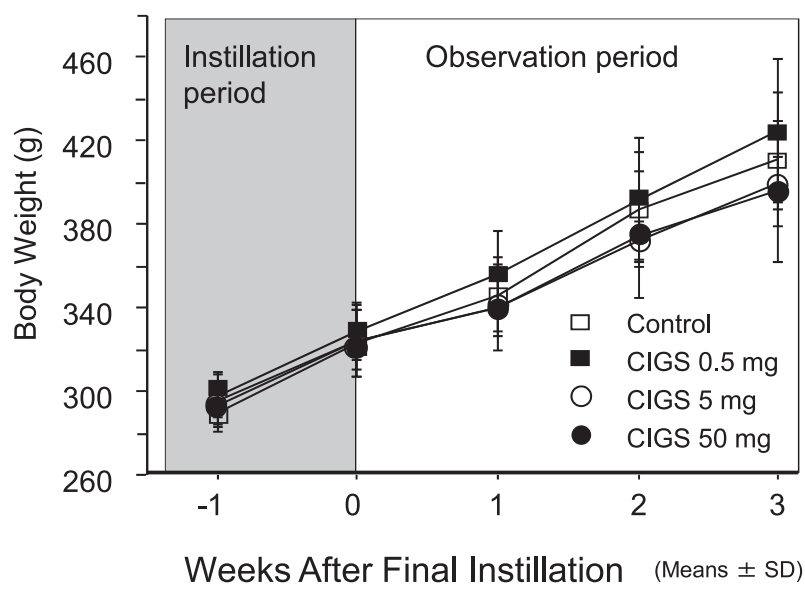

Fig. 1. Changes in body weight gain among the three CIGS groups during the instillation and observation periods. The results shown are means \pm SD of rats euthanized at 3 wk. Statistical significance was determined by two-way repeated measure ANOVA.

not lead to any suppression in body weight gain. Changes in body weight among the CIGS groups throughout the observation period are shown in Fig. 1 for the 21 animals ( 5 in the CIGS $0.5 \mathrm{mg}$ group, 5 in the CIGS $5 \mathrm{mg}$ group, 6 in the CIGS $50 \mathrm{mg}$ group and 5 in the control group) observed until 3 wk after the final instillation. There was no significant difference between the CIGS groups and the control group at each time point. Mean body weight (mean \pm SD) at $3 \mathrm{wk}$ was $425.2 \pm 34.5 \mathrm{~g}$ in the CIGS $0.5 \mathrm{mg}$ group, $399.7 \pm 12.6 \mathrm{~g}$ in the CIGS $5 \mathrm{mg}$ group, $395.9 \pm 34.1 \mathrm{~g}$ in the CIGS $50 \mathrm{mg}$ group and $411.5 \pm 32.1 \mathrm{~g}$ in the control group. No systemic signs such as respiratory distress, dermatologic abnormality and behavioral or neurological disorder appeared during the observation period in any of the groups.

The changes in relative lung weight during the observation period are shown in Fig. 2. The relative lung weights in the CIGS $5 \mathrm{mg}$ and CIGS $50 \mathrm{mg}$ groups were significantly higher those that in the CIGS $0.5 \mathrm{mg}$ group and control group at each time point. Moreover, the CIGS $50 \mathrm{mg}$ group demonstrated higher lung weights than the CIGS $5 \mathrm{mg}$ group at $3 \mathrm{wk}$, and the CIGS $0.5 \mathrm{mg}$ group demonstrated higher lung weights than the control group at $3 \mathrm{wk}$ following the final instillation, with the differences being significant.

The serum metal concentrations during the observation period for all the CIGS groups are shown in Table 1. In and $\mathrm{Ga}$ were detected in the CIGS $5 \mathrm{mg}$ and $50 \mathrm{mg}$ groups but not in the $0.5 \mathrm{mg}$ and control groups. The serum In concentrations in the CIGS $5 \mathrm{mg}$ and $50 \mathrm{mg}$ groups and the serum Ga concentrations in the CIGS $5 \mathrm{mg}$ group gradually increased 


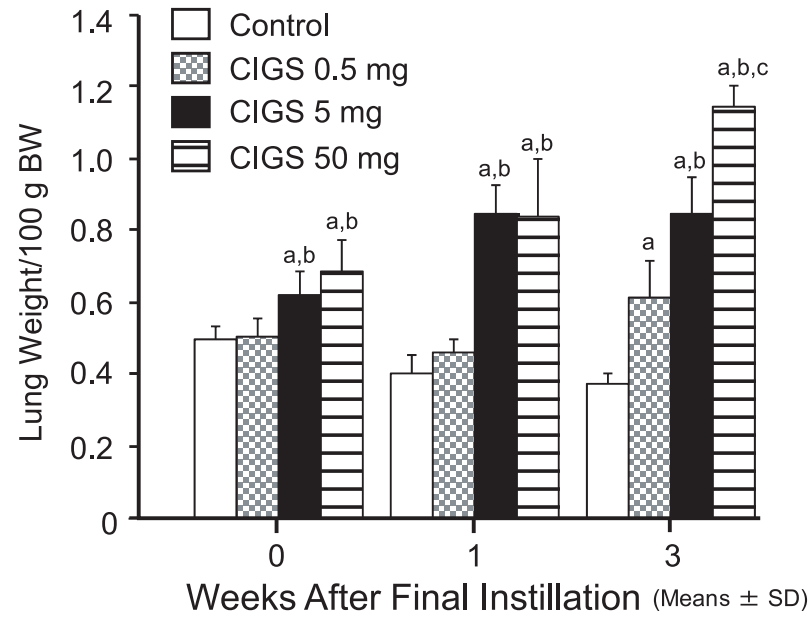

Fig. 2. Changes in relative lung weight from the final instillation. The results shown are means $\pm \mathrm{SD}$ of relative lung weights of rats euthanized at each time point. Statistical significance was determined by Fisher's least significant difference procedure after one-way analysis of variance. a: Significant differences are indicated compared with the control group $(p<0.05)$. b: Significant differences are indicated compared with the CIGS $0.5 \mathrm{mg}$ group $(p<0.05)$. c: Significant differences are indicated compared with the CIGS $5 \mathrm{mg}$ group $(p<0.05)$. from 0 to $3 \mathrm{wk}$, while the serum Ga concentration sharply decreased from 0 to $3 \mathrm{wk}$ in the CIGS $50 \mathrm{mg}$ group. Furthermore, the serum In and $\mathrm{Ga}$ levels increased depending on the dose instilled at each time point. Instillation of CIGS particles had almost no influence on the serum $\mathrm{Cu}$ and $\mathrm{Se}$ concentrations at each time point, although the CIGS $5 \mathrm{mg}$ group and CIGS $50 \mathrm{mg}$ group showed a significant decrease at $3 \mathrm{wk}$ and increase at $0 \mathrm{wk}$, respectively, compared with the control group.

The metal contents in the lung during the observation period are shown in Table 2 . There was no appreciable pulmonary clearance of $\mathrm{Cu}, \mathrm{In}, \mathrm{Ga}$ or Se among the CIGS-treated rats until the end of observation period, even though the metal content increased slightly at $1 \mathrm{wk}$ in the CIGS $5 \mathrm{mg}$ group only. The content of each metal in the lung in each CIGS groups rose dose-dependently until the end of the observation period. However, extremely small amounts of $\mathrm{Cu}$ and $\mathrm{Se}$ were detected, but not of In and $\mathrm{Ga}$, in the lung of the control group at each time point.

The severity of pathologic change in the lungs is shown in Table 3 . The pulmonary pathological changes in the CIGS-treated groups were almost

Table 1. Metal concentration of $\mathrm{Cu}, \mathrm{In}, \mathrm{Ga}$ and $\mathrm{Se}$ in serum after intratracheal instillation of CIGS

\begin{tabular}{|c|c|c|c|c|}
\hline \multirow{2}{*}{ Element $\mu \mathrm{g} / l$} & \multirow{2}{*}{ Group } & \multicolumn{3}{|c|}{ Weeks after final instillation (wk) } \\
\hline & & 0 & 1 & 3 \\
\hline \multirow{4}{*}{$\mathrm{Cu}$} & Control & $1,306.2 \pm 169.2$ & $1,473.4 \pm 114.6$ & $1,555.8 \pm 242.7^{\mathrm{c}}$ \\
\hline & CIGS $0.5 \mathrm{mg}$ & $1,347.0 \pm 52.6$ & $1,443.2 \pm 122.1$ & $1,543.2 \pm 56.0^{c}$ \\
\hline & CIGS $5 \mathrm{mg}$ & $1,343.8 \pm 92.0$ & $1,487.8 \pm 241.5$ & $1,259.6 \pm 63.3^{\mathrm{b}, \mathrm{c}}$ \\
\hline & CIGS 50 mg & $1,476.0 \pm 86.3$ & $1,339.2 \pm 178.2$ & $1,483.7 \pm 57.2$ \\
\hline \multirow{4}{*}{ In } & Control & $-^{\mathrm{a}}$ & - & - \\
\hline & CIGS $0.5 \mathrm{mg}$ & - & - & - \\
\hline & CIGS $5 \mathrm{mg}$ & $3.9 \pm 3.1$ & $15.4 \pm 5.4^{\mathrm{c}}$ & $9.7 \pm 3.6$ \\
\hline & CIGS 50 mg & $39.9 \pm 8.4^{\mathrm{b}}$ & $46.0 \pm 20.7^{b}$ & $78.1 \pm 19.9^{b, c, d}$ \\
\hline \multirow{4}{*}{$\mathrm{Ga}$} & Control & - $^{\mathrm{a}}$ & - & - \\
\hline & CIGS $0.5 \mathrm{mg}$ & - & - & - \\
\hline & CIGS $5 \mathrm{mg}$ & $8.6 \pm 13.7$ & $10.8 \pm 7.5$ & $13.3 \pm 26.1$ \\
\hline & CIGS 50 mg & $388.8 \pm 85.0^{\mathrm{b}}$ & $68.5 \pm 35.3^{\mathrm{b}, \mathrm{c}}$ & $70.5 \pm 18.4^{\mathrm{b}, \mathrm{c}}$ \\
\hline \multirow{4}{*}{$\mathrm{Se}$} & Control & $788.2 \pm 101.1$ & $852.6 \pm 90.5$ & $1,028.2 \pm 147.0^{\mathrm{c}, \mathrm{d}}$ \\
\hline & CIGS $0.5 \mathrm{mg}$ & $854.5 \pm 88.1$ & $929.8 \pm 28.8$ & $1,042.0 \pm 85.7^{\mathrm{c}}$ \\
\hline & CIGS $5 \mathrm{mg}$ & $882.8 \pm 57.0$ & $925.2 \pm 155.8$ & $1,001.2 \pm 85.2$ \\
\hline & CIGS 50 mg & $954.5 \pm 54.2^{\mathrm{b}}$ & $945.2 \pm 89.7$ & $1,156.7 \pm 132.6^{\mathrm{c}, \mathrm{d}}$ \\
\hline
\end{tabular}

The results are shown as means \pm SD.

a: The value was below the quantitative limit of each metal. b: Significantly different from the control group at each time point $(p<0.05)$. c: Significantly different from $0 \mathrm{wk}$ among the same CIGS group $(p<0.05)$. d: Significantly different from $1 \mathrm{wk}$ among the same CIGS group $(p<0.05)$. 
Table 2. Metal contents of $\mathrm{Cu}, \mathrm{In}, \mathrm{Ga}$ and $\mathrm{Se}$ in the lung after intratracheal instillation of CIGS

\begin{tabular}{clccc}
\hline \multirow{2}{*}{ Element (mg/Lung) } & \multicolumn{1}{c}{ Group } & \multicolumn{3}{c}{ Weeks after final instillation (wk) } \\
\cline { 3 - 5 } & & 0 & 1 & 3 \\
\hline \multirow{3}{*}{$\mathrm{Cu}$} & Control & $0.003 \pm 0.000$ & $0.002 \pm 0.001$ & $0.002 \pm 0.000$ \\
& CIGS 0.5 mg & $0.055 \pm 0.014$ & $0.043 \pm 0.022$ & $0.059 \pm 0.021$ \\
& CIGS 5 mg & $0.260 \pm 0.186$ & $0.536 \pm 0.221^{\mathrm{b}}$ & $0.210 \pm 0.097$ \\
& CIGS 50 mg & $4.098 \pm 0.922$ & $2.386 \pm 1.723$ & $3.341 \pm 2.937$ \\
\hline \multirow{3}{*}{$\mathrm{In}$} & Control & - $^{\mathrm{a}}$ & - & - \\
& CIGS 0.5 mg/kg & $0.043 \pm 0.015$ & $0.031 \pm 0.021$ & $0.047 \pm 0.016$ \\
& CIGS 5 mg/kg & $0.231 \pm 0.166$ & $0.461 \pm 0.179^{\mathrm{b}}$ & $0.205 \pm 0.071$ \\
& CIGS 50 mg & $3.804 \pm 0.791$ & $2.384 \pm 1.409$ & $2.783 \pm 1.480$ \\
\hline \multirow{3}{*}{$\mathrm{Ga}$} & Control & $-{ }^{\mathrm{a}}$ & - & - \\
& CIGS 0.5 mg & $0.029 \pm 0.009$ & $0.021 \pm 0.014$ & $0.031 \pm 0.011$ \\
& CIGS 5 mg & $0.154 \pm 0.113$ & $0.311 \pm 0.118^{\mathrm{b}}$ & $0.134 \pm 0.046$ \\
& CIGS 50 mg & $2.673 \pm 0.561$ & $1.622 \pm 0.941$ & $1.884 \pm 1.006$ \\
\hline \multirow{3}{*}{$\mathrm{Se}$} & Control & $0.001 \pm 0.000$ & $0.001 \pm 0.000$ & $0.001 \pm 0.000$ \\
& CIGS 0.5 mg & $0.106 \pm 0.035$ & $0.077 \pm 0.053$ & $0.115 \pm 0.037$ \\
& CIGS 5 mg & $0.596 \pm 0.425$ & $1.195 \pm 0.433^{\mathrm{b}}$ & $0.517 \pm 0.182$ \\
& CIGS 50 mg & $10.062 \pm 2.037$ & $6.205 \pm 3.489$ & $7.152 \pm 3.653$ \\
\hline
\end{tabular}

The results are shown as means $\pm \mathrm{SD}$.

a: The value was below the quantitative limit of each metal. b: Significantly different from the CIGS $5 \mathrm{mg}$ group at $0 \mathrm{wk}$ and $1 \mathrm{wk}(p<0.05)$.

Table 3. Pathological changes in the rat lung after intratracheal instillation of CIGS

\begin{tabular}{llccc}
\hline \multirow{2}{*}{ Pathological changes } & Group & \multicolumn{3}{c}{ Weeks after final instillation (wk) } \\
\cline { 3 - 5 } & & 0 & 1 & 3 \\
\hline \multirow{2}{*}{$\begin{array}{l}\text { Inflammatory response with diffuse hyperplasia of } \\
\text { the bronchiolar-alveolar epithelium }\end{array}$} & CIGS 0.5 mg & \pm & \pm & + \\
& CIGS 5 mg & + & + & + \\
& CIGS 50 mg & $2+$ & $3+$ & $3+$ \\
& Control & - & - & - \\
\hline \multirow{2}{*}{ Exudation within the alveolar spaces } & CIGS 0.5 mg & - & - & \pm \\
& CIGS 5 mg & - & \pm & + \\
& CIGS 50 mg & - & + & $3+$ \\
& Control & - & - & - \\
\hline
\end{tabular}

The severity of the lung lesions was categorized by five grades: - , negative; \pm , slight; + , mild; $2+$, moderate; and $3+$, severe.

the same morphologically. Diffuse foci of slight to severe inflammation were present in all the CIGS groups from 0 to $3 \mathrm{wk}$. In all the CIGS-treated groups, the alveolar septa in the region of the inflammatory foci were diffusely lined with a hyperplastic alveolar epithelium or regenerative epithelium with mild cellular atypia, and infiltration of inflammatory cells to the alveolar spaces or bronchiolar lumen was seen. Inflammatory cells were observed within the alveolar spaces or bronchiolar lumen. They mostly consisted of neutrophils, mixed with a few alveolar macrophages, and mononuclear cells. Alveolar macrophages with an expanded cytoplasm or including
CIGS particles were seen within the alveolar spaces (Fig. 3). The degrees of inflammatory response depended on the dose given in the CIGS-treated groups. Exudation, including mucinous edema-like exudation partially positive for PAS and necrotic cell debris within the alveolar spaces, was seen to a slight to severe degree in the CIGS-treated groups from 1 to $3 \mathrm{wk}$, but not at $0 \mathrm{wk}$. Most of the individual CIGS particles or aggregates of these particles were present in the alveolar spaces, bronchiolar lumens, interstitial tissue and lymphoid tissue around bronchioles in the lung. Furthermore, deposition of these particles was observed in the lymph nodes in the CIGS-treated 

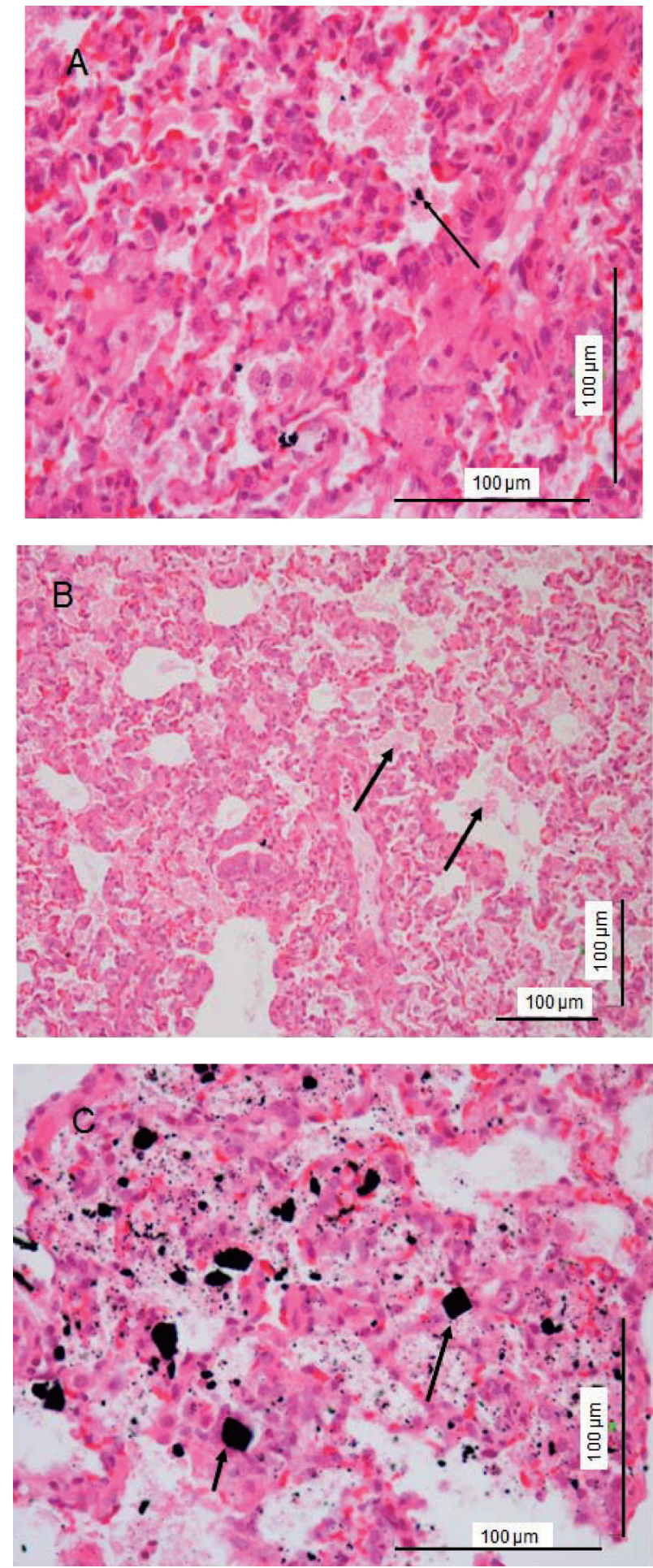

Fig. 3. Photomicrograph of lungs showing inflammatory changes. (A) A rat in the CIGS $0.5 \mathrm{mg}$ group at $3 \mathrm{wk}$. Macrophages showing expanded cytoplasm containing CIGS particles (arrow) are apparent. H \& E stain. (B) A rat in the CIGS $5 \mathrm{mg}$ group at $3 \mathrm{wk}$. Exudation in the alveolar spaces (arrow) is evident. $\mathrm{H} \& \mathrm{E}$ stain. (C) A rat in the CIGS $50 \mathrm{mg}$ group at $3 \mathrm{wk}$. Necrotic cell debris and numerous CIGS particles (arrow) in the alveolar spaces are apparent. H \& E stain. groups. These particles were continuously seen in the lung from 0 to $3 \mathrm{wk}$ in the CIGS-treated groups. Cholesterol clefts in the alveolar spaces and interstitial fibrotic proliferation did not manifest among the CIGS-treated groups from 0 to $3 \mathrm{wk}$. No inflammatory response, hyperplastic lesions or exudation within the alveolar spaces was evident in the control group.

\section{Discussion}

In the current study, subacute pulmonary toxicity of CIGS particles was demonstrated by instillation into the lungs of rats. This is apparently the first report to evaluate the subacute pulmonary toxicity of CIGS particles. Almost all lung lesions, in which the degree of lung lesion manifestation depended on the dose of CIGS particles instilled, continued to be evident throughout the observation period among all the CIGS groups. Furthermore, since a considerable quantity of CIGS particles resided within the lung up to 3 wk after the last instillation, we suspect that CIGS particles are poorly dissolved in the lung after intratracheal instillations in rats and as a result causes a sustained inflammatory reaction in the lung. Although there was no definitive conclusion concerning whether development of lung lesions was due to the effect of $\mathrm{Cu}$, In, Ga or Se released from the CIGS particles, it seemed that the main causative factor contributing to the persistent manifestation of lung lesions was CIGS particles themselves.

On the other hand, CIGS particles instilled into the lung lead to increased concentrations of In and $\mathrm{Ga}$ in serum, not for $\mathrm{Cu}$ and Se. Morgan et al. reported the pulmonary toxicity of copper indium diselenide (CIS) or copper gallium diselenide (GCS) after an intratracheal instillation and that CIS caused greater pulmonary toxicity than $\mathrm{CGS}^{30,31)}$. They suggested that the greater toxicity of CIS may be due to differences in the toxicities of In and Ga. Furthermore, they showed that In was detected, but not $\mathrm{Ga}$, in serum after an instillation of CIS or CGS particles intratracheally. In the present study, In and Ga were detected in both the CIGS $5 \mathrm{mg}$ and $50 \mathrm{mg}$ groups dose-dependently but not in the CIGS $0.5 \mathrm{mg}$ and control groups in serum. Since hardly any In and Ga was released to the blood from CIGS particles in the lung after instillation of a very small amount of CIGS particles into the lung, it appears that there is a threshold dose of CIGS deposition in the lung that results in In and $\mathrm{Ga}$ being detected in serum. Although serum In and Ga may be effective biological monitoring markers of exposure to CIGS particles, we cannot ignore the possibility of exposure to CIGS particles in CIGS handling work, even if $\mathrm{In}$ and $\mathrm{Ga}$ are not detected in the sera of workers.

Previously, we reported the serum In level when 
an equimolar amount of InAs or InP particles was instilled into the lungs of hamsters ${ }^{11)}$. The serum In level in the InAs- or InP-treated hamsters showed the highest level at $0 \mathrm{wk}$ after the final instillation, subsequently decreasing gradually until $88 \mathrm{wk}$. Recently, we reported the chronic pulmonary toxicity of $3 \mathrm{mg} / \mathrm{kg}$ or $6 \mathrm{mg} / \mathrm{kg}$ of ITO particles and of $2.7 \mathrm{mg} / \mathrm{kg}$ or $5.4 \mathrm{mg} / \mathrm{kg}$ of indium oxide $\left(\mathrm{In}_{2} \mathrm{O}_{3}\right)$ particles containing $2.2 \mathrm{mg} / \mathrm{kg}$ or $4.5 \mathrm{mg} / \mathrm{kg}$ of indium per instillation when given to hamsters in repeated intratracheal instillations over a 4 mo period $^{17)}$. The serum indium concentrations of all ITO- or $\mathrm{In}_{2} \mathrm{O}_{3}-$ treated groups gradually increased up to the end of the observation period, in contrast with InAs and InP. In the present study, however, although there was no additional exposure to CIGS particles at $3 \mathrm{wk}$ after the final instillation, the serum In level did in fact increase in the CIGS $5 \mathrm{mg}$ and $50 \mathrm{mg}$ groups from 0 to $3 \mathrm{wk}$ after the final instillation, as seen with the instillation of ITO and $\operatorname{In}_{2} \mathrm{O}_{3}$. However, the serum Ga level showed the highest level at $0 \mathrm{wk}$ after the final instillation in the CIGS $50 \mathrm{mg}$ group and subsequently decreased rapidly at $1 \mathrm{wk}$. On the other hand, the biological half-life of serum Ga was $87 \mathrm{~min}$ for the fast component and $24.5 \mathrm{~h}$ for the slower component after gallium nitrate was administered to patients ${ }^{36}$. The clearance of Ga was very slow from the lung after inhalation of gallium oxide in rats during $13 \mathrm{wk}$, and excretion of $\mathrm{Ga}$ was fast from organs and blood after it was absorbed in the body ${ }^{32}$. It seems that metabolism of In and $\mathrm{Ga}$ in serum is different; the biological half-life in serum is very long for In but is short for Ga.

To date, there is no data available concerning the health effects of workers engaged in the process of CIGS handling. However, several cases of lung disorder, mainly interstitial pneumonia, caused by inhaled ITO have been published ${ }^{25-29)}$, since the first case report involving death ${ }^{21)}$. These cases showed a high serum indium level and high sialylated carbohydrate antigen, Krebs von den Lungen-6 (KL-6) (standard level $<500 \mathrm{U} / \mathrm{m} l$ ), level, interstitial changes in the lung on high-resolution computed tomography (HRCT) or pneumothorax. Regarding the epidemiological study of indium compounds, Chonan et al. ${ }^{22)}$ reported interstitial pulmonary disorders in indium-processing workers. Their study was performed on 108 male workers in an indium plant. Twenty-three workers showed interstitial changes in the lung on HRCT, and 40 workers showed an increased high level of serum KL-6. The serum indium level among the workers was related to the KL-6 level and also to the degree of HRCT change. Furthermore, Hamaguchi et al. ${ }^{20)}$ reported that indium compounds cause interstitial lung damage in indium-exposed workers. Elevated serum indium concentration and a higher level of KL-6, SP-D or SP-A among 93 workers exposed to indium were observed when compared with those in 93 workers with no such exposure. On the other hand, Nakano et al. ${ }^{24)}$ performed an epidemiological study among currently exposed indium workers and formerly exposed indium workers, in which dosedependent lung effects due to indium exposure were revealed, and a decrease in indium exposure reduced the lung effects. From their result, it is considered that improvement of the working environment for handling CIGS is very effective for reduction of the health risk.

The National Toxicology Program (NTP) ${ }^{13)}$ and Gottschling et al. ${ }^{12)}$ reported that InP caused lung benign and malignant tumors when rats and mice were exposed to its particles, and they stated that oxidative stress played a major role in the development of lung tumors induced by InP exposure. Although carcinogenic evidence has been adequately demonstrated for InP in animals, it has been inadequately studied in humans. Based on the above studies, InP was evaluated as probably carcinogenic to humans (Group 2A) by the IARC ${ }^{33)}$. Nevertheless, based on the evidence of the carcinogenicity of InP and because the carcinogenicity of the indium compound is strongly doubted, additional animal studies focusing on long-term observation are required to confirm the effects of CIGS particles with regard to carcinogenicity, toxic manifestation and the clearance of CIGS particles from the lung. We are currently carrying out this type of study.

In conclusion, subacute pulmonary toxicity of CIGS particles was confirmed, and CIGS clearance from the lung was considerably slow when repeated intratracheal instillations were given to rats. Therefore, a great deal of attention should be paid to exposure to CIGS particles in the handling process for CIGS.

Acknowledgments: This study was funded in part by Grants-in-Aid for Scientific Research (B) (19390164 and 23390164) from the Ministry of Education, Culture, Sports, Science and Technology of Japan and the Incorporated Administrative Agency New Energy and Industrial Technology Development Organization (NEDO) under the Ministration of Economy, Trade and Industry (METI).

The English used in this manuscript was revised by Miss K. Miller (Royal English Language Centre, Fukuoka, Japan).

\section{References}

1) Contreras MA, Ramanathan K, AbuShama J, et al. Diode characteristics in state-of-the art $\mathrm{ZnO} / \mathrm{CdS} /$ $\mathrm{Cu}\left(\mathrm{In}_{1-\mathrm{x}} \mathrm{Ga}_{\mathrm{x}}\right) \mathrm{Se}_{2}$ solar cells. Prog Photovoltaics Res 
Appl 2005; 13: 209-16.

2) Tolcin AC. Indium. In: U.S. Geological Survey Minerals yearbook-2008. Volume I. - Metals and Minerals. U.S. Geological Survey, [Online]. 2008 [cited 2010 Jun 10]; Available from: URL: http:// minerals.usgs.gov./minerals/pubs/commodity/indium/ myb1-2008-indiu.pdf

3) Arumu Publishing Co. Solar cell and Silicon raw materials. In: Industrial rare metals, No.125. Tokyo: Arumu Publishing Co; 2009. p.12-3 (in Japanese).

4) Arumu Publishing Co. Indium: In: Industrial rare metals, No. 127, Tokyo, Arumu Publishing Co.; 2011. p.118-9 (in Japanese).

5) Tanaka A, Hisanaga A, Hirata M, Omura M, Inoue N, Ishinishi N. Pulmonary toxicity of indium arsenide and arsenic selenide following repeated intratracheal instillations to the lungs of hamsters. Appl Organomet Chem 1994; 8: 483-94.

6) Zheng W, Winter SM, Kattnig MJ, Carter DE, Sipes IG. Tissue distribution and elimination of indium in male Fischer 344 rats following oral and intratracheal administration of indium phosphide. J Toxicol Environ Health 1994; 43: 483-94.

7) Tanaka A, Hisanaga A, Hirata M, et al. Chronic toxicity of indium arsenide and indium phosphide to the lungs of hamsters. Fukuoka Acta Medica 1996; 87: $108-15$.

8) Oda K. Toxicity of a low level of indium phosphide (InP) in rats after intratracheal instillation. Ind Health 1997; 35: 61-8.

9) Uemura $T$, Oda K, Omae K, et al. Effects of intratracheally administered indium phosphide on male Fischer 344 rats. J Occup Health 1997; 39: 205-10.

10) Tanaka A, Hirata $M$, Omura $M$, et al. Comparative study of the toxic effects of gallium arsenide, indium arsenide and arsenic trioxide following intratracheal instillations to the lung of Syrian golden hamsters. Fukuoka Acta Medica 2000; 91: 21-33.

11) Yamazaki $K$, Tanaka $A$, Hirata $M$, et al. Long term pulmonary toxicity of indium arsenide and indium phosphide instilled intratracheally in hamsters. J Occup Health 2000; 42: 169-78.

12) Gottschling BC, Maronpot RR, Hailey JR, et al. The role of oxidative stress in indium phosphide-induced lung carcinogenesis in rats. Toxicol Sci 2001; 64: $28-40$.

13) National Toxicology Program (NTP). Toxicology and carcinogenesis studies of indium phosphide (CAS No. 22398-80-7) in F344/N rats and B6C3F1 mice (inhalation studies), NTP TR 499. U.S. Department of Health and Human Services, Public Health Service, National Institutes of Health; 2001. p.1-348.

14) Tanaka A, Hirata M, Omura M, et al. Pulmonary toxicity of indium-tin oxide and indium phosphide after intratracheal instillations into the lung of hamsters. J Occup Health 2002; 44: 99-102.

15) Tanaka A, Hirata M, Omura M. Pulmonary squamous cyst induced by exposure to indium arsenide in hamsters. J Ocup Health 2003; 45: 405-7.

16) Linson D, Laloy J, Corazzari I, et al. Sintered indi- um-tin-oxide (ITO) particles: a new pneumotoxic entity. Toxicol Sci 2009; 108: 472-81.

17) Tanaka A, Hirata M, Homma $T$, et al. Chronic pulmonary toxicity study of indium-tin oxide and indium oxide following intratracheal instillations into the lungs of hamsters. J Occup Health 2010; 52: $14-22$.

18) Nagano K, Gotoh K, Kasai T, et al. Two- and 13-week inhalation toxicities of indium-tin oxide and indium oxide in rats. J Occup Health 2011; 53: $51-63$.

19) Nagano K, Nishizawa T, Umeda $Y$, et al. Inhalation carcinogenicity and chronic toxicity of indium-tin oxide in rats and mice. J Occup Health 2011; 53: 175-87.

20) Nagano K, Nishizawa T, Eitaki Y, et al. Pulmonary toxicity in mice by 2 - and 13 week inhalation exposures to indium-tin oxide and indium oxide aerosols. J Occup Health 2011; 53: 234-9.

21) Homma $T$, Ueno $T$, Sekizawa $K$, Tanaka A, Hirata M. Interstitial pneumonia developed in a worker dealing with particles containing indium-tin oxide. J Occup Health 2003; 45: 137-9.

22) Chonan T, Taguchi O, Omae K. Interstitial pulmonary disorders in indium-processing workers. Eur Respir J 2007; 29: 317-24.

23) Hamaguchi T, Omae K, Takebayashi $T$, et al. Exposure to hardly soluble indium compounds in ITO production and recycling plants is a new risk for interstitial lung damage. Occup Environ Med 2008; 65: 51-5.

24) Nakano M, Omae K, Tanaka A, et al. Causal relationship between indium compound inhalation and effects on the lungs. J Occup Health 2009; 51: 513-32.

25) Homma S, Miyamoto A, Sakamoto S, Kishi K, Motoi N, Yoshimura K. Pulmonary fibrosis in an individual occupationally exposed to inhaled indiumtin oxide. Er Respir J 2005; 25: 200-4.

26) Taguchi O, Chonan T. Three cases of indium lung. J Jpn Respir Soc 2006; 44: 532-5 (in Japanese).

27) Nakano M, Kamata H, Saito F, et al. A case of indium lung diagnosed by worker's health examination. Occup Health J 2007; 30: 25-9 (in Japanese).

28) Cummings KJ, Donat WE, Ettensohn DB, Roggli VL, Ingram P, Kreiss K. Pulmonary alveolar proteinosis in workers at an indium processing facility. Am J Respir Crit Care Med 2010; 181: 458-64.

29) Xiao YL, Cai HR, Wang YH, Meng FQ, Zhang DP. Pulmonary alveolar proteinosis in an indiumprocessing worker. Chi Med J 2010; 123: 1347-50.

30) Morgan L, Shines CJ, Jeter SP, et al. Acute pulmonary toxicity of copper gallium diselenide, copper indium diselenide, and cadmium telluride intratracheally instilled into rats. Environ Res 1995; 71: 16-24.

31) Morgan L, Shines CJ, Jeter SP, et al. Comparative pulmonary absorption, distribution, and toxicity of copper gallium diselenide, copper indium diselenide, and cadmium telluride in Sprague-Dawley rats. 
Toxicol Appl Pharmacol 1997; 147: 399-410.

32) IARC. Gallium arsenide, cobalt in hard metals and cobalt sulfate, gallium arsenide, indium phosphide and vanadium pentoxide. IARC Monographs on the Evaluation of Carcinogenic Risks to Humans. Vol. 86. Lyon (France): IARC; 2006. p.163-96.

33) IARC. Indium phosphide, cobalt in hard metals and cobalt sulfate, gallium arsenide, indium phosphide and vanadium pentoxide. IARC Monographs on the Evaluation of Carcinogenic Risks to Humans. Vol. 86. Lyon (France): IARC; 2006. p.197-224.

34) IARC. Overall evaluations of carcinogenicity: An updating of IARC Monographs Volumes 1 to 42 Suppl 7. Lyon (France): IARC; 1987. p.100-6.

35) Ishizuka S, Yamada A, Shibata $\mathrm{H}$, et al. Large grain $\mathrm{Cu}$ (In, Ga) $\mathrm{Se}_{2}$ thin film using a Se-radical beam source. Solar Energy Materials \& Solar Cells 2009; 93: 792-6.

36) Krakoff IH, Newman RA, Goldberg RS. Clinical toxicologic and pharmacologic studies of gallium nitrate. Cancer 1979; 44: 1722-79. 